he was often not sturdy enough, physically and mentally, to handle the load that he imposed on himself. This was compounded by his sometimes shaky marriage to a fragile and not always faithful woman. That he produced so much despite all this is remarkable. The portrait that emerges is of a refined intellectual of the highest ethical standards, unwilling or unable to advocate effectively on his own behalf - even accepting his wife's demand that their children should not attend the Nobel ceremonies. Although he was a refugee from Nazi Germany, he was profoundly disturbed to see his beloved pure physics spawning nuclear weapons in the hands of some of his most talented students: Robert Oppenheimer, Edward Teller, Victor Weisskopf and the spy Klaus Fuchs.

So does this book fill what is a serious gap in the history of twentieth-century physics? In contrast to the other great figures in the quantum revolution, Born's personality has never been described in any depth, and this part of

the gap is filled exceptionally well. As for Born's science, the job is done for the physicist, who can apply well-informed opinions to grade the significance of the people and discoveries described. But other readers would have benefited from an account of Born's work that did a better job of separating the wheat from the chaff.

All the book's readers would have benefited had the editor insisted that we do not need to know the names of all those Alpine hotels the Borns visited, what they ate there, and a barrage of other details. This mass of minutae often produces a haze that could make it hard for readers to see what is most exceptional and long-lasting among Born's many achievements. Nevertheless, there is no question that any future work on Born will find this book to be an indispensable study of this major figure in one of the most profound transformations in the history of science.

Kurt Gottfried is in the Physics Department, Cornell University, Ithaca, New York 14853, USA.

\title{
Acting on instinct
}

\section{Patterns of Behavior: Konrad Lorenz, Niko Tinbergen, and the Founding of Ethology by Richard W. Burkhardt, Jr \\ University of Chicago Press: 2005. 636 pp. \\ $\$ 80, £ 56$ (hbk); \$29, £20.50 (pbk)}

\section{Johan J. Bolhuis}

The Austrian Konrad Lorenz and Dutchman Niko Tinbergen founded ethology, the study of animal behaviour, at the start of the twentieth century. The history of the 'study of instinct', as it was once known, attracts interest from a range of disciplines, and this naturally affects the viewpoint of books on the subject. Niko's Nature (Oxford University Press, 2003), for example, a recent biography of Tinbergen, was written by his one-time friend and pupil Hans Kruuk (for a review see Nature 427, 293-294; 2004). In contrast, Richard Burkhardt is a historian, not an ethologist, so his book Patterns of Behavior is quite different. Nevertheless, it is not a dry factual biography of a scientific discipline, but a fascinating and often entertaining account of the life and work of some of ethology's key figures. Burkhardt has done a tremendous job, meticulously analysing and describing the rise of ethology. He consulted a multitude of written sources and interviewed many of the important players.

Modern history of science is not only about scientific concepts, Burkhardt explains, but is just as much about the social context of the individual scientists - what he likes to call "ethology's ecologies". The term 'ethology' was introduced by the American William Wheeler, and US biologists active around the end of the nineteenth century might have contributed much more to the development of ethology if they'd had the resources and the intellectual freedom to pursue their empirical studies and develop new ideas. A particularly poignant example of this is the pioneering biologist Wallace Craig, who greatly influenced Lorenz but struggled to make ends meet for most of his life. When the great British ethologist William Thorpe lectured at Harvard in 1951, he paid tribute to his American colleagues Charles Otis Whitman, Wheeler and Craig. Thorpe was surprised that only one or two members of his large audience seemed to know who Craig was. According to Burkhardt: "Thorpe, supposing Craig was dead, was astonished to learn that Craig was not only alive but in the audience."

The development of ethology has been greatly influenced by the different personalities involved. Nowhere is this shown more clearly than in the relationship between the two key figures in the field, Lorenz and Tinbergen. The characters of these two men could hardly have been more different. Whereas Lorenz was vain, self-centred, an extrovert and a self-styled philosopher, Tinbergen was modest, an introvert and an empiricist. Lorenz characterized himself as a 'farmer', who mainly observed the domesticated birds that he kept around his own house, in contrast to the 'hunter', Tinbergen, who conducted controlled experiments both in the field and in the laboratory. The contrast between the two men became painfully obvious during the Second World War, when Lorenz was a doctor in the German army and Tinbergen was interred in a detention camp for Dutch intellectuals. Burkhardt devotes an entire chapter to Lorenz's conduct during the Nazi regime, and shows that, blinded by ambition, Lorenz did not distance himself from Nazi doctrine. After the war it took some time for the wounds to heal so that the two friends could resume their scientific partnership.

One of Tinbergen's lasting contributions is the identification of the four main problems in animal behaviour: evolution, function, development and causation. Tinbergen has credited British biologist Julian Huxley with identifying three of these as the main problems in biology, to which he merely added development. On reading Burkhardt's account, however, it seems that Tinbergen was being rather generous towards Huxley. "It is from a failure to distinguish between ultimate cause, immediate

IMAGE
UNAVAILABLE
FOR COPYRIGHT
REASONS


cause, and mere necessary machinery, that so much of the barren disputes of biology are due," wrote Huxley. It would seem that, with such a sloppy and essentially misguided interpretation, these disputes would not be solved in a hurry. Unfortunately, even Tinbergen's careful analysis of cause and function could not prevent a confusion of concepts that continues to this day.

Some will say that ethology is no longer a scientific discipline in its own right, but that depends on who you ask: a behavioural ecologist and a cognitive ethologist might give you different answers. Nevertheless, Burkhardt notes that the core ideas of classical ethology dissipated astonishingly rapidly; few contemporary ethologists would use such concepts as 'action-specific energy', for example. This discarding of outmoded ideas would seem natural for any vibrant scientific discipline.

Burkhardt rightly maintains that it was the empirical and theoretical approach introduced by Lorenz, Tinbergen and their colleagues that made the study of animal behaviour what it is today. In order to study the genomic or neural mechanisms of behaviour, we need to know how behaviour works, and for that an ethological analysis is crucial. This wonderful book shows very clearly how early ethologists made such analysis possible.

Johan J. Bolhuis is in the Department of Biology,

Utrecht University, Padualaan 14,

3584 CH Utrecht, The Netherlands.

\section{DANCE}

\section{Einstein in motion}

\section{Constant Speed \\ Rambert Dance Company \\ At Sadler's Wells, London, 24-28 May \\ 2005. UK tour begins September 2005. \\ www.rambert.org.uk}

\section{Alison Wright}

I admit, I cringed when I heard that the UK Institute of Physics (IOP) had commissioned a ballet to celebrate the World Year of Physics 2005, or 'Einstein Year'. Truly enlightening meetings of art and science are rare indeed. Einstein: The Ballet? Please, no.

But the IOP had wisely put themselves in the hands of the Rambert Dance Company, and the results, revealed at a Sadler's Wells première on 24 May, are stunning.

Constant Speed is inspired by Einstein's 1905 publications; the World Year of Physics celebrates their centenary. From the patent office in Bern, Switzerland, Einstein dashed off five papers, all of them seminal work, on three themes: brownian motion, the photoelectric effect and the special theory of relativity.

Relativity, and $E=m c^{2}$, will be forever associated with Einstein. But it is his work on the photoelectric effect, which established the notion of the 'quantum', that Einstein himself regarded as his most revolutionary. The effect describes the release of electrons from a metal when light is shone on its surface. To explain the relation between the energy of the electrons released and the frequency of the incident light, Einstein proposed that light energy is transferred to the electrons in distinct chunks, or quanta. No less significant was his study of fluctuation phenomena within the framework of kinetic-molecular theory - work that recalled the brownian motion seen in the dance of pollen grains in water decades earlier.

Choreographer Mark Baldwin, the artistic director of the Rambert, developed Constant Speed through conversations with Ray Rivers, professor of theoretical physics at Imperial College London. Although he claims to be ignorant of physics, Baldwin was struck by a similarity of language - space, time, energy between physics and dance. Quite rightly, I

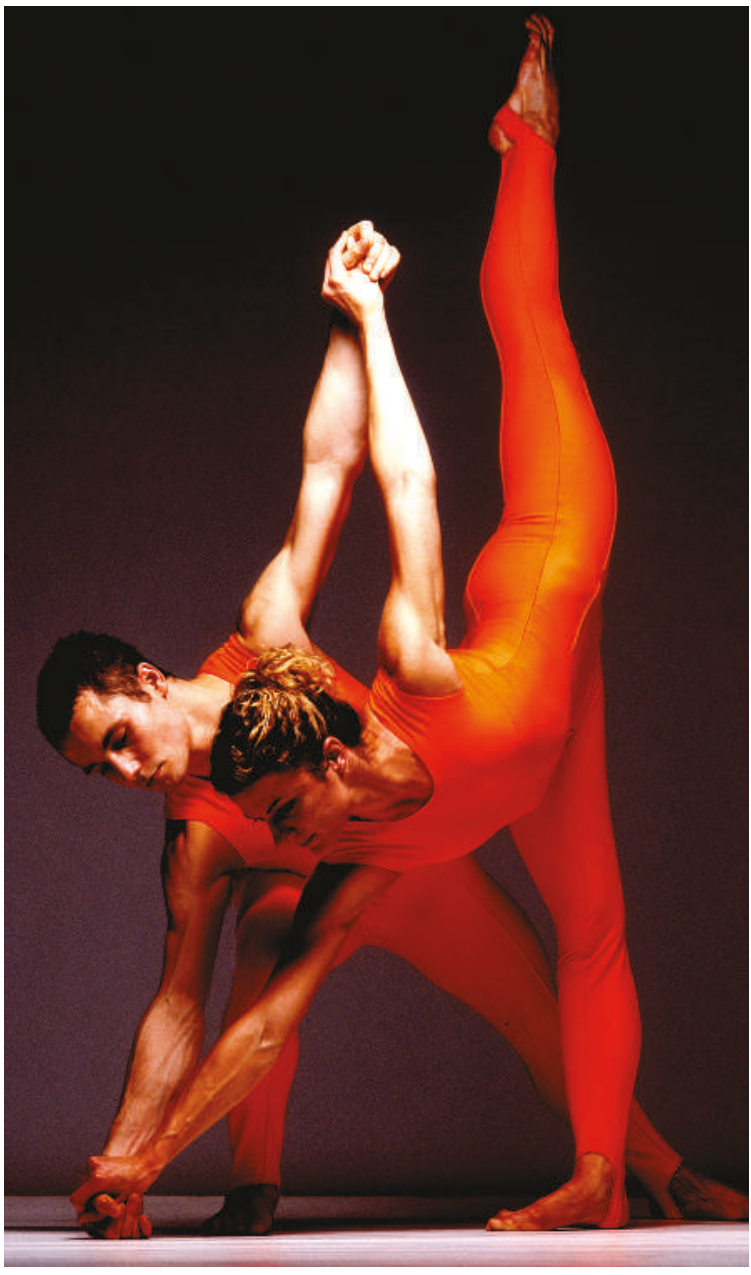

Getting physical: dancers of the Rambert Dance Company.

metallic stage is bathed in light. Or they could be photons, tight packets of energy that also have concerted, wave-like motions. Then the whiteness is subsumed by red, with red lighting and red costumes as more dancers join the fray, evolving eventually through the full spectrum of colour. The colour-coded dancers are compartmentalized - quantized, if you like - each pair exploring its own motion at its own frequency until the rainbow finale. The music by Franz Lehár, composed like Einstein's physics in 1905, adds another dimension: you can almost imagine Einstein day-dreaming, seeing the multicoloured quanta of his theory before him as he hummed along to the pop music of his day.

At just 27 minutes long, the swirling colour of Constant Speed seemed to be over all too quickly. But the work was superbly complemented by the preceding programme, especially Momenta, created by Rambert dancer Mikaela Polley. To music by Patrick Nunn, the dance builds steadily in energy, speed and coherence (more physics!). Different moods were created by the tawdry humour of the opening piece, Judgement of Paris, and the heart-rending emotion of Dark

think, he shied away from specifically representing relativity in the piece, alluding only in the title to that theory's central tenet of a constant speed of light. Brownian motion, on the other hand, is a concept easily reflected in the movements and configuration of the dancers. But it is the ideas surrounding the photoelectric effect that dominate Constant Speed.

Running on to the stage, fists clenched and elbows pumping, the white-clad dancers could be photoelectrons, released as the seemingly
Elegies. However, the maturity of these pieces, choreographed by Anthony Tudor in the 1930s, perhaps highlighted a few rough edges in Constant Speed.

The physics is there if you look - but don't look too hard. As Baldwin said, this is not a physics lesson. Rather, Constant Speed is about inspiration: inspiring physics and inspired dance.

Alison Wright is the editor of Nature Physics.

www.nature.com/naturephysics 